\title{
Exilio y transtierro en dos poemas de Gonzalo Rojas
}

\author{
Exile and transterment in two poems by Gonzalo Rojas
}

Nelson Rojas

Universidad de Nevada, World Languages, Reno, Nevada, Estados Unidos.

Correo electrónico: rojas@unr.edu

Como muchos intelectuales de nuestra época, el poeta Gonzalo Rojas (Lebu, 1916-2011) vivió la casi siempre traumática experiencia del exilio, experiencia que aparece transmutada en diversos poemas de su obra. Este artículo tiene por objetivo estudiar el tema del exilio en la poética del autor, para lo cual se han seleccionado dos poemas en que el tema ocupa el primer plano: "Domicilio en el Báltico", aparecido impreso por vez primera en Oscuro (1977), y "Transtierro", del volumen homónimo publicado en 1979. El enfoque metodológico empleado es un análisis semántico-comparativo de ambos poemas, auxiliado por aspectos extratextuales relativos a la biografía del autor y al contexto de producción de los poemas. El resultado de la investigación indicaría que aunque se aprecian preocupaciones afines en ambos poemas -la angustia de una futura muerte fuera de la tierra natal, por ejemplo-, hay diferencias patentes. A la transparente reacción del hablante frente a un entorno geográfico, cultural y político explícito de "Domicilio en el Báltico", se contraponen las densas inquietudes metafísicas del hablante de "Transtierro", quien discurre sobre los posibles avatares de su vida en el exilio.

Palabras clave: exilio, Gonzalo Rojas, "Domicilio en el Báltico", "Transtierro”, análisis semántico-comparativo

As has been the case with many intellectuals in our time, the poet Gonzalo Rojas (Lebu, 19162011) lived the almost always traumatic experience of exile, which appears in many poems of his work. To meet the objective of his article -the theme of exile in the poetics of the authortwo poems have been selected in which this theme occupies center stage: "Domicilio en el Báltico", which appeared in print form for the first time in Oscuro (1977) and "Transtierro", published in the volume of the same name in 1979. The methodological approach employed is a semantic-comparative analysis of both poems assisted by extra textual information related to the author's biography and the contexts in which the poems were produced. This research shows that even though one finds common concerns in both poems -the anguish of a possible future death away from one's native land, for instance- there are evident differences. The poetic speaker's transparent reaction to a specific geographical, cultural and political setting in "Domicilio en el Báltico" contrasts with the intense metaphysical apprehensions of the speaker of "Transtierro", who contemplates the possible transformations his life in exile will undergo.

Key words: exile, Gonzalo Rojas, "Domicilio en el Báltico", "Transtierro", semanticcomparative analysis 
Como muchos intelectuales de nuestra época, el poeta Gonzalo Rojas (Lebu, 1916-2011) vivió la casi siempre traumática experiencia del exilio, experiencia que aparece transmutada en diversos poemas de su obra. Este artículo tiene por objetivo estudiar el tema del exilio en la poética del autor, para lo cual se han seleccionado dos poemas en que el tema ocupa el primer plano: "Domicilio en el Báltico", aparecido impreso por vez primera en Oscuro (1977), y “Transtierro", del volumen homónimo publicado en 1979. El enfoque metodológico empleado es un análisis semánticocomparativo de ambos poemas, auxiliado por aspectos extratextuales relativos a la biografía del autor y al contexto de producción de los poemas. El resultado de la investigación indicaría que aunque se aprecian preocupaciones afines en ambos poemas -la angustia de una futura muerte fuera de la tierra natal, por ejemplo-, hay diferencias patentes. A la transparente reacción del hablante frente a un entorno geográfico, cultural y político explícito de "Domicilio en el Báltico", se contraponen las densas inquietudes metafísicas del hablante de "Transtierro", quien discurre sobre los posibles avatares de su vida en el exilio.

Antes de entrar en materia, mencionaré unos breves datos sobre el poeta y su vida para contextualizar los dos poemas en cuestión. Gonzalo Rojas (con quien comparto apellido) nació en Lebu, en el extremo sur de Chile, en 1916 ${ }^{1}$. Hasta antes de los exilios de los cuales hablaremos, Gonzalo Rojas había publicado dos poemarios, La miseria del hombre en 1948, y Contra la muerte dieciséis años más tarde, en 1964. En 1972 se instala en Cuba como agregado cultural, y posteriormente como encargado de negocios. En 1973 el presidente Salvador Allende lo nombra embajador en Cuba, pero el golpe de estado del 11 de septiembre que depone el gobierno de la Unidad Popular le impide asumir el cargo. El poeta permanece en Cuba. Unas pocas semanas después del golpe, el 19 de octubre de 1973, el gobierno militar emite un decreto en que lo expulsa de todas las universidades chilenas por constituir "un peligro para el orden y la seguridad interna" (May 1991: 205)². Su pasaporte queda invalidado y sólo el siguiente año, en marzo de 1974, es acogido por la entonces República Democrática Alemana. Llega a la ciudad de Rostock, ubicada a orillas del mar Báltico, con cargo de catedrático de la Universidad de Rostock, sin embargo, no se le asigna ninguna clase, por no estar el programa de estudio que presentó dentro de la línea ideológica académico-política de esa institución. Obtenía, así, un sueldo sin trabajar. En este plazo se escribe el primer poema que comentaremos, "Domicilio en el Báltico”, que será publicado más tarde en el volumen Oscuro (1977).

El año siguiente, en 1975, usando pasaportes antiguos, deja la República Oriental Alemana y llega a Venezuela, en donde le ofrecen una cátedra en la Universidad Simón Bolívar de Caracas. En 1977, la editorial caraqueña Monte Ávila publica su poemario Oscuro, y en 1979 aparece Transtierro, publicado en Madrid, volumen que incluye el otro poema que comento, que lleva el mismo título que el volumen, "Transtierro". En septiembre de 1979 logra regresar a Chile, pero, falto de trabajo, debe pronto salir de nuevo, y ejerce como catedrático en diversas universidades

Generalmente se cita 1917 como el año del nacimiento, fecha que es un error, como se explica, por ejemplo, en la nota de Ricardo Bada (2011). Luego comienza a enmendarse el error, como puede verse en la cronología compilada por Rodrigo Rojas-Mackenzie (s/f), o en la información sobre el poeta que aparece en el sitio del Centro Virtual Cervantes, entre otros: http://cvc.cervantes.es/literatura/escritores/rojas/default.htm.

2 Hay que apuntar que Hilda R. May ofrece en este libro una visión bastante completa de la vida y obra del poeta, incluyendo el período que comento. 
estadounidenses, publica numerosos poemarios, dicta conferencias, lee sus poemas, y, sólo a partir de 1994, Chile vuelve a ser su residencia permanente.

$\mathrm{Su}$ labor poética comienza a recibir reconocimientos oficiales temprano en la década de los 90. El poeta es el primer galardonado con el Premio de Poesía Reina Sofía en 1992, año en que también recibe el Premio Nacional de Literatura, en 1997 recibe dos premios, el Premio Octavio Paz y el Premio José Hernández de Argentina, y en 2003 se le otorga el Premio Cervantes, máximo galardón de las letras hispanas. Desde la publicación de Transtierro en 1979, y hasta poco antes de su muerte, ha seguido la publicación ininterrumpida de obras; dos últimas aparecieron en 2010 un poco antes de su muerte: El sol es la única semilla y Con arrimo y sin arrimo. El poeta fallece en abril de 2011. En marzo de 2013 aparece el libro Íntegra, en edición de la investigadora Fabienne Bradu, el que recoge su obra poética completa, y en que comentarios o datos pertinentes acompañan a la mayoría de los poemas.

Para situar de modo breve el fenómeno del exilio, se debe mencionar que se inscribe dentro de los desplazamientos humanos, usándose generalmente el término migración, con sus subclases de inmigración y emigración, para referirse a los movimientos que tienen principalmente causas económicas, y reservándose el término exilio para desplazamientos motivados por razones políticas (Cymerman 1993: 523). La información biográfica anotada anteriormente muestra los movimientos geográficos realizados por Gonzalo Rojas durante su experiencia en el exilio, experiencia casi nunca placentera. Said anota que ésta es una vivencia "terrible de experimentar", y que se caracteriza por ser una "grieta imposible de cicatrizar impuesta entre un ser humano y su lugar natal” (2005: 179).

Aunque por razones de extensión examinaré sólo dos visiones del exilio en la obra de Gonzalo Rojas, cabe hacer un par de puntualizaciones para ubicar el tema dentro de la obra total del autor. En primer lugar, este tema aparece en varios otros poemas, tal vez de modo no tan central como en los poemas que analizaré. Así, por ejemplo, en el poema “Diáspora 60", cuyo título resume el sexagésimo cumpleaños del poeta y su vida en el exilio, se evoca el doloroso año del derrocamiento de Salvador Allende, fecha que desencadena exilios en muchos intelectuales del país, y se cita unas líneas más adelante el comienzo del salmo 137, que alude al exilio de los israelitas en Babilonia:

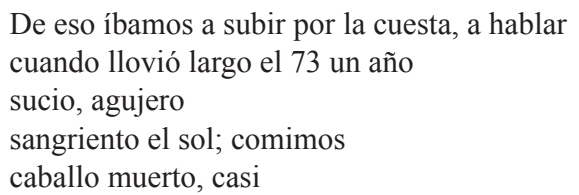

super flumina Babylonis, illic sedimus

et flevimus, un cuchillo

por cítara, (...) (1979: 111).

Igualmente, unas líneas del movimiento 5 del poema "Turpial A-6B", en que "Turpial" nombra el edificio y "A-6B" el apartamento en que vivió el poeta en Caracas, nos comunican el estado de ánimo del hablante:

(...) y es tan difícil, todo es tan difícil, la tristeza, 
el trópico, este mismo A-6B

en sus metros de vidrio, (...) (1979: 29-30).

Los dos poemas recién citados aparecieron originalmente en Transtierro. Un poema publicado un poco antes, en Oscuro, es "Celia", evocación de la madre en uno de los aniversarios de su muerte, ocurrida el 13 de agosto de 1940. Al comienzo del movimiento 3 del poema, el hablante se duele de que el exilio le impida llevar flores a la tumba materna:

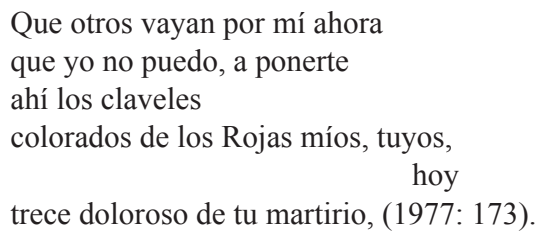

Unas líneas más adelante, al final del poema, en caso que nadie pueda llevar esas flores, sola la madre, entonces, el hablante querría tenerla junto a él, en el exilio también:

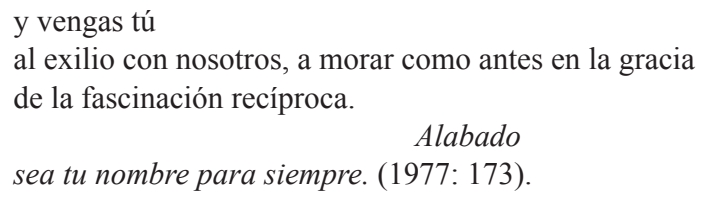

Citaré, finalmente, del poema "Materia de testamento" del poemario homónimo, la escueta línea en que el hablante lega al exilio dos objetos que evocan experiencias funestas: "al exilio un par de zapatos sucios y un traje baleado" (1988: 40).

La segunda puntualización es que en la obra del autor el tema del exilio es uno solamente dentro de varios. En el prólogo de su poemario Materia de testamento (1988: 16), el poeta ve tres vertientes esenciales en su obra: lo numinoso (en el sentido de das Heilege 'lo santo', del filósofo y teólogo alemán Rudolf Otto), lo erótico, y lo real inmediato, vertiente esta última en la que caben los dos poemas examinados en este artículo. Marcelo Coddou (1999), en la compilación Obra selecta, ve seis categorías en que se pueden agrupar los poemas del autor, y llama a la sección en que aparecen los dos poemas estudiados "El testimonio político, pero sin consignas"3. Por su parte, Hilda R. May (1991) detalla y estudia diez aspectos de la obra de Gonzalo Rojas, e incluye los dos poemas en cuestión en la sección que se titula "Lo político y la experiencia del exilio"4.

Paso ahora a comentar el poema "Domicilio en el Báltico", dos estrofas de verso libre, de nueve líneas cada una, de desigual extensión, y que abrevio "Domicilio" de aquí en adelante.

Las otras categorías son: el oficio mayor; lo numinoso; lo erótico; lo tanático y lo elegíaco, y; la genealogía de la sangre y del espíritu.

$4 \quad$ Las otras nueve secciones llevan por título: la conciencia del oficio desde un ars poetica persistente; lo genealógico en su doble vertiente: la imaginaria y la sanguínea; lo mágico desde una versión fisiológica; lo numinoso; lo tanático y lo elegíaco; humor y desenfado; lo exótico; existencia y metafísica, y; la circunstancia inmediata. 
Tendré que dormir en alemán, aletear, respirar si puedo en alemán entre tranvía y tranvía, a diez kilómetros de estridencia amarilla por hora, con esta pena a las 5.03, ser exacto y silencioso en mi número como un lisiado más de la guerra, mimetizarme coleóptero blanco.

Envejecer así, pasar aquí veinte años de cemento previo al otro, en este nicho prefabricado, barrer entonces la escalera cada semana, tirar la libertad a la basura en esos tarros grandes bajo la nieve, agradecer, sobre todo en alemán agradecer, supongo, a Alguien. (1977: 201).

La primera estrofa está centrada en aspectos de la vida del hablante en el nuevo domicilio, aspectos que remecen su ser y su identidad. Inicialmente, destaca la presencia del idioma foráneo que lo invade todo, incluso, exagerando, el respirar; a su alrededor ya no escucha su lengua natal, elemento definidor de todo poeta, su verdadero hogar -Hilda R. May (1999: 218-219) hace acertadas apuntaciones con respecto a la relación exilio-lengua extranjera-. El ritmo de su vida está regido ahora por la exactitud de los números. Los tranvías corren a una velocidad determinada y llegan a un destino a una hora también determinada; el hablante se siente identificado por medio no de un nombre sino de un número, tal como una persona a quien la guerra ha incapacitado. Además, ya no se siente como un ser humano sino como un insecto casi invisible ("mimetizarme coleóptero / blanco"). Está clara su desorientación tanto externa como interna.

La segunda estrofa puede dividirse en dos momentos. En las primeras seis líneas el hablante proyecta su vida hacia el futuro, y sólo ve aflicción, desconsuelo y amargura. El frío cemento de la casa en que vive es un anticipo del cemento de la necrópolis en que reposará su cuerpo una vez muerto; su vida está regulada por menesteres domésticos -barrer, deshacerse de... la libertad, no de desperdicios como uno esperaría, palabra que, en este contexto, puede incluirse dentro del mismo campo semántico que barrer-. Aparecen aquí dos imágenes superpuestas, la patente de tirar la libertad a la basura y la latente de tirar los desperdicios a la basura. Los desperdicios latentes contaminan la libertad patente y equivalen a un juicio de valor que iguala ambos términos. En estas dos acciones de eliminación -barrer, tirar- es donde se toca la pérdida que más se deplora -la pérdida de una vida en libertad-. En "tirar la libertad / a la basura", que encubre la acción repetida periódicamente de desechar basura a que nos compele la sociedad, se pone al descubierto de modo manifiesto el control político; junto con la basura depositada en contenedores, también se deposita allí la libertad.

Me he detenido en esta frase porque ha sido interpretada como una aseveración del hablante válida básicamente para él y la vida que lleva, pero también como una crítica 
a todo el sistema político del país en que reside. Enrique Giordano concuerda más con la visión crítica de un individuo que resulta válida únicamente para él: "el poeta (...) se encuentra arrojado en una sociedad que ignora su identidad por completo"; y añade: el poema no es "una condena al socialismo y, por lo tanto, es ocioso tratar de encontrar entre líneas algún manifiesto ideológico anti-marxista" (1987: 214). Aunque el contexto del poema, escrito en primera persona singular, lleva al lector por el camino de la crítica hecha por el hablante y limitada a él, nada impide que se tome a este hablante como portavoz de voces disidentes. En realidad, el poeta mismo, más tarde, ha avalado la interpretación de crítica al sistema político socialista en cuanto práctica, no en cuanto utopía teórica, como se lee en la entrevista concedida al catedrático Enrique Foffani (2002). Así, a la pregunta de si se debe entender "Domicilio" como una condena al socialismo, el poeta responde: "El año que pasé en Rostock fue de tormento. Se me terminó de caer el socialismo como sistema, no en cuanto utopía, desde que comienzo a registrar el estado policial" (Foffani 2002: en línea)

El segundo momento de la segunda estrofa son las tres últimas líneas del poema, en las que Giordano ve "ironía sin humor" (1987: 213). Es el momento del agradecimiento. Ya que el hablante ha sido acogido en un nuevo domicilio, las reglas de los deberes del forastero obligan a agradecer, algo que bien podría haber aparecido al comienzo del poema. Sin embargo, estas líneas finales no constituyen en absoluto una expresión de gratitud. Primeramente están debilitadas por el inciso dubitativo "supongo", luego porque el hablante se autoimpone el uso del nuevo idioma que, en realidad, no es un requisito sine qua non del agradecimiento; lo que prima es el agradecimiento, no la lengua en que se expresa. Además, el destinatario del agradecimiento no es, como podría suponerse, una divinidad (como en la frecuente expresión "doy gracias a Dios", divinidad que llevaría mayúscula); tampoco se agradece a una persona u organización o al país mismo que lo ha acogido, lo que también aparecería con mayúscula; se agradece a un destinatario vacío, anónimo, mentado por el insustancial pronombre indefinido Alguien, el cual normalmente no lleva mayúscula. El mensaje es entonces, efectivamente, que dada la vida que lleva en este nuevo domicilio no caben los agradecimientos, no hay razón para agradecer a nadie. Éste es un poema de una experiencia de desazón y pesadumbre sufrida por un hablante encerrado en un suelo extraño, rodeado por sonidos extraños, en un medio de vida también extraño; un hablante que vive en un domicilio tumba en donde su liberación es la muerte. Una experiencia de este tipo no exige agradecimiento alguno.

Hago finalmente unas breves apuntaciones sobre aspectos formales que aparecen en el poema. En el plano fónico, la aliteración en la línea 2 de las sílabas iniciales ale-, atan el nombre del idioma del nuevo lugar, alemán, con el infinitivo aletear, que no es un vivir pleno sino un vivir sin vuelo, como apunta Giordano (1987: 213); se refuerza así el impacto pernicioso de la lengua foránea en el hablante. Asimismo, en las líneas 3 y 4 el tranvía y sus estridencias comparten el poco melodioso grupo consonántico tr. En el plano gráfico, las sangrías en las líneas 6 y 16 dan realce, sucesivamente, a la vida en que impera la frialdad de los números exactos y al agradecer que, como se vio, no es realmente tal. Ya se comentó la mayúscula que lleva el pronombre indefinido Alguien, lo cual enfatiza la importancia de lo anónimo

Hilda R. May ve este poema como un vaticinio de lo que le ocurrirá más tarde a la URSS, pero concuerda con Giordano en cuanto al alcance político crítico limitado del poema (1991: 208-209). 
en la experiencia que se describe. En el plano estructural, se nota un continuo interrumpir del pensamiento que se refleja en los numerosos encabalgamientos de verso a verso, como, por ejemplo, en la primera estrofa entre las líneas 3 y 4,4 y 5 , 5 y 6,8 y 9 , y 9 y 10 . Desde el punto de vista sintáctico, todo el poema es una sola oración, articulada en una cláusula principal -tendré que-, seguida por una serie de complementos encabezados por un infinitivo: tendré que dormir, aletear, respirar, etc., hasta llegar al infinitivo final: tendré que agradecer, como se hace explícito en el esquema que sigue. Nada se hace motu proprio; todo es obligación; no hay libertad.

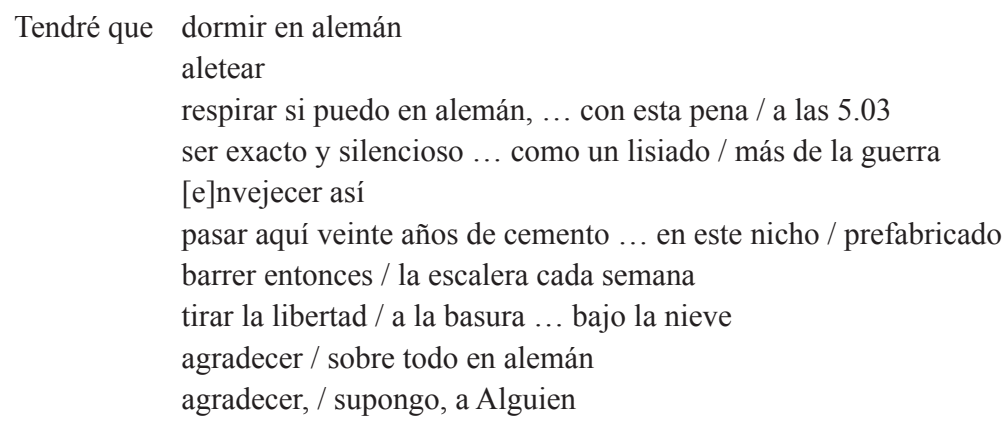

Paso ahora a comentar el poema "Transtierro" aparecido en el volumen del mismo nombre ${ }^{6}$.

Miro el aire en el aire, pasarán

estos años cuántos de viento sucio

debajo del párpado cuántos

del exilio,

2

comeré tierra

de la Tierra bajo las tablas

del cemento, me haré ojo,

oleaje me haré

parado

en la roca de la identidad, este

hueso y no otro me haré, esta

música mía córnea

4

por hueca.

Parto

soy, parto seré.

Parto, parto, parto.

\footnotetext{
El apartado "Sobre el poema "Transtierro", de mis Estudios sobre la poesía de Gonzalo Rojas (1984), contiene detalladas observaciones, la mayoría no incluidas en este artículo, acerca de aspectos morfológicos, sintácticos y fónicos de este poema.
} 
En primer lugar, apunto una breve observación sobre el título del poema. La palabra transtierro, copiada evidentemente sobre el esquema morfológico prefijo + la raíz tierr- o terr- del sustantivo tierra, como se ve en las palabras entierro y destierro, la usó el filósofo español José Gaos para hablar de algunos de los afectados por la diáspora causada por la guerra civil española. Se quería distinguir entre aquellos que se sentían perdidos, totalmente alienados en su nuevo medio (los que sufrían el destierro), y aquellos que se encontraban en un medio lingüístico y cultural afín (México, por ejemplo), en que la integración a la nueva residencia era más fácil (los que experimentaban un transtierro). Así, Ascunce anota que "la disparidad de país, lengua, cultura, costumbres, etc., origina en éstos [i.e., en los que sufren el destierro, el exilio] un sentimiento claro de extranjería, difícil, en ocasiones imposible, de superar", mientras que entre los que sufren el transtierro "desde una perspectiva lingüística y cultural se da una identidad completa, favoreciendo una integración más fácil y plena por los elementos de unidad entre el país de origen y la cultura-tierra de adopción" (2002: 271-272).

Usando la distinción destierro versus transtierro, se podría decir que hubo destierro del hablante (o si se prefiere de Gonzalo Rojas) en Rostock, y transtierro luego en Caracas. Tal distinción, sin embargo, no parece aplicarse en el caso del poeta chileno, para quien residir tanto en Alemania Oriental como en Venezuela parece haberse sentido como residencia transitoria; el propósito no fue de asentarse en esos nuevos domicilios sino regresar a la tierra natal, lo que se logró en 1979, y de modo realmente definitivo en 1994. Hilda R. May también señala que el país natal nunca está ausente en la obra del poeta cuando apunta que "[e]n esta poesía, cuando se habla del exilio, hay un paisaje interior, hay un hablante lírico que vive siempre en estrecha comunión con su tierra madre creada y recreada dentro de su mente" (1991: 221). De este modo, transtierro parece significar simplemente un trasplante, un pasar de una tierra a otra tierra, que no es la tierra deseada ${ }^{7}$.

En segundo lugar, respecto a una lectura del poema mismo, el poeta parece indicar que consta de cuatro unidades, cada una encabezada por los dígitos sucesivos del poema. No obstante, tal división no resiste análisis, ya que la frase preposicional "por hueca" que comienza el movimiento \#4 pertenece por sentido al movimiento \#3. Querría, entonces, proponer que el contenido del poema permite aislar tres unidades semánticas básicas, a saber:

- El presente, que incluye casi todo el movimiento \#1 del poema.

- El futuro y sus devenires, que comprende la forma del futuro "pasarán" del movimiento \#1, los movimientos \#2 y \#3, y la primera línea del movimiento \#4.

- El parir/partir envuelto en la palabra parto, incluido en las tres últimas líneas del movimiento \#4.

En la primera unidad semántica, el presente, vemos un ojo que contempla aire, un espacio vacuo, en que nada ocurre: "Miro el aire en el aire". El poema anterior nos mostraba parte de la vida de la ciudad (tranvías desplazándose a una velocidad

En realidad, el concepto de transtierro va más allá de tierra entendida como entidad geográfica, como lo indican estas líneas del prólogo del poemario Transtierro: "Transtiérrate, le digo entonces a mi alma, y verás. El origen verás, la patria honda del transtierro. Que es Tierra y más, palabra viva y rehallazgo; aquí, allá, sin nadie, con Quevedo" (1979: 7). 
determinada, por ejemplo), y algunas de las actividades del hablante (barrer las escaleras). En este poema no se aprecia el entorno geográfico; hay sólo un ojo activo que mira al vacío, un vacío en que el aire que se mueve -el viento- le resulta sucio al hablante. Para el ojo-testigo del hablante, este exilio constituye un lugar vaciado, sin belleza alguna.

En la segunda unidad semántica, la más extensa, el hablante se ve ya muerto, y aunque hay cemento como en el poema anterior, hay también tierra, elemento en que van a ocurrir las transformaciones que se vivirán en el trans+tierro, en el pasar de una tierra a otra, de un espacio a otro. El poeta se hará sucesivamente ojo (ese ojotestigo del primer movimiento), se hará oleaje sobre una roca, la cual representa su identidad, se volverá hueso y finalmente música. Al mimetismo insectil que se veía en el "coleóptero / blanco" de "Domicilio", transformación menguada y degradante, se suma en "Transtierro" un crescendo de transformaciones: el ojo inicial del poema; el oleaje con rocas de esos mares del sur de la patria en que se crio, fundamento de su identidad; la solidez del hueso y, finalmente, su verdadera identidad, la música. Esta última recibe dos atributos un tanto inesperados, córnea y hueca, que parecieran restarle realce al sustantivo. El adjetivo córnea evoca primariamente la dureza del cuerno, y se emparienta con el hueso y la roca, elementos mentados unas líneas antes en el poema, pero también evoca secundariamente el cuerno como instrumento musical y su profundo sonido, lo cual lo inscribe en el mundo de la música. De modo semejante, el adjetivo hueca pareciera llevar de nuevo al vacío del comienzo del poema, pero también remite a las acepciones retumbante y profunda aplicadas a la voz, como se lee, por ejemplo, en el diccionario de la Real Academia Española; estamos entonces igualmente en el ámbito del sonido y de la música. Al hablante no le espera el futuro desolador de "Domicilio", sino uno más acorde con su calidad de poeta: el hablante se transformará en su música, en su poesía ${ }^{8}$.

La última unidad semántica tiene como centro la palabra polisémica parto, tanto sustantivo como forma del presente de indicativo del verbo partir. Así, esta forma aúna, entre otras, la idea del nacimiento, de comienzo de la vida, y también la de una partida formulada por el hablante, que puede referirse a una partida especial y definitiva, la de la muerte 9 . La palabra parto es la primera de esta unidad y, por su situación al final de la línea 14, deja abierta la doble interpretación aludida de sustantivo o de verbo. La línea siguiente elimina uno de los significados, ya que la forma del verbo ser que sigue ("Parto / soy") le asigna a parto la categoría de sustantivo. El hecho de que tras el sustantivo parto haya un verbo en presente seguido de otro en futuro (parto/ soy, parto seré), nos habla de un nacimiento que no morirá. En la última línea donde se observa la repetición triple de parto, caben ambas interpretaciones de sustantivo o de verbo; el final del poema, puede ser la

\footnotetext{
Marcelo Pellegrini, interesado en rastrear el origen de la poética de Gonzalo Rojas, resbaladiza empresa, ofrece una lectura diferente del poema tanto en su conjunto como en detalles. Razones de espacio y enfoque de este trabajo impiden una evaluación de la hipótesis general: "Transtierro" como una "pieza clave para entender las reflexiones riojanas sobre los orígenes, siendo también un poema que se escapa de ellas" (2013: 195). En cuanto a detalles, cabe mencionar en este lugar que la palabra córnea, adjetivo en el texto, como vimos, es interpretada por Pellegrini como sustantivo y, siendo la córnea una parte constitutiva del ojo, se une con la visión del primer movimiento.

$9 \quad$ Hilda R. May (1991: 175) alude también a la pareja parir/partir como una importante "clave bisémica" presente en
} varios de los poemas del autor. 
despedida, yo parto ${ }^{10}$, o el nacimiento, el parto perpetuo. Es un final que no cierra el mensaje, sino que lo deja abierto con una imagen de muerte/vida, que en otros contextos de la obra de este poeta y de otros no constituye una dicotomía, sino un solo concepto, mentado por Vicente Huidobro (1941) con la palabra híbrida muervida. No hay en este poema un mensaje de desesperanza, sino todo lo contrario, el hablante o bien reafirma el concepto del nacimiento tres veces, o bien nos dice que comienza (comienza $=$ parto, verbo) otro viaje, o que comienza el viaje en que todos habitamos, tanto vivos como muertos.

Cabe anotar diversos elementos formales que realzan el contenido del poema. Como en el poema anterior, la disposición gráfica muestra encabalgamientos y sangrías determinadas por el final del verso anterior al comienzo de las partes 2, 3 y 4, lugares donde se pone en relieve, respectivamente, la tierra; el hecho de que, muerto, estará parado, enhiesto y no tendido; la cualidad córnea de su música y, lo que es más importante, la anfibología de la palabra parto, ya anotada. Hay palabras clave que se repiten: aire, único elemento externo mencionado, cuántos, para indicar la duración del exilio que parece sin fin, tierra/Tierra, y una vez más, parto, cinco veces. Hay también medidas rítmicas que pueden aislarse, según la lectura semántica que se haga del poema (versos heptasílabos: miro el aire en el aire; alejandrinos: pasarán / estos años cuántos de viento sucio; eneasílabos: comeré tierra / de la Tierra, etc. ${ }^{11}$.

Contrastando ambos poemas, es interesante señalar que la relativa transparencia semántica de "Domicilio" frente a la mayor densidad semántica de "Transtierro" se puede apreciar nítidamente en el empleo de la puntuación -en el uso, "mal uso" o falta de uso de estos signos-. No es preciso mencionar el uso normal del punto final que señala el fin del discurso. No debe tampoco sorprender que en las líneas no finales de estos poemas haya un empleo mínimo de los signos de puntuación (sólo comas y puntos), ni que este uso no siga en todo momento las normas que registran los manuales de ortografía. Ésta es una de las herencias de la ruptura que significaron las vanguardias de comienzo del siglo pasado, movimientos que eligieron la invención y la aventura, y no la tradición y el orden, para decirlo con palabras de Guillaume Apollinaire ([1918] 1987) en su poema "La jolie rousse".

En "Domicilio" la puntuación sigue muy de cerca la sintaxis del poema que, como se señaló, incluye la cláusula principal Tendré que seguida por cláusulas subordinadas de infinitivo, cada una separada por una coma. Una de estas cláusulas subordinadas interiores, sin embargo, pareciera irregular ya que termina en punto y no en coma. Ese punto se justifica porque separa las actividades de la primera estrofa que ocurren en el presente (y que seguramente continuarán), frente a las proyecciones hacia el futuro en la segunda estrofa. El punto, entonces, es una marca visible de dos momentos temporales diferentes del poema.

En "Transtierro" la puntuación del movimiento \#4 es normal. El primer punto señala el fin de las trasformaciones en que evolucionará el hablante, los otros dos puntos marcan el fin de las dos oraciones finales, y las comas son pausas menores

10 Dejo de lado la posible interpretación de (yo) parto con el significado de (yo) separo, por ser un verbo transitivo que quedaría mejor con su complemento directo (lo que no ocurre), y por estar este significado alejado del resto semántico del poema. En Pellegrini (2013: 195) se incluye también este sentido.

11 Hay observaciones adicionales sobre el ritmo de este poema en el apartado ya mencionado "Sobre el poema 'Transtierro"' (Rojas 1984: 103-105). 
dentro de esas oraciones. En el resto del poema, que sólo contiene comas, la puntuación no sigue las normas usuales. El sentido permite aislar oraciones, pausas mayores, que podrían llevar puntos en lugar de las comas que aparecen en el poema ${ }^{12}$. El fragmento de oración -"esta / música mía córnea / por hueca"- en que se subentiende un inicial "me haré", va precedido de coma como las otras oraciones que llevan ese mismo pronombre + verbo. Hay un signo de puntuación que, desde el punto de vista del discurso normal, está ausente. El fin del movimiento \#2 requiere una pausa menor que debería ir indicada por una coma, coma que no aparece y no se incluye porque la coma se ha usado para pausas mayores; la pausa se indica por el término del movimiento \#2 y el paso al siguiente movimiento - hay versiones que colocan un punto en ese lugar, lo que no va con el resto de ese movimiento-. Mención merece también la falta de puntuación del adverbio cuántos, repetido dos veces en el primer movimiento, el cual podría haber sido precedido y seguido de uno o más signos de puntuación; el mejor sería la raya o la raya y los signos de exclamación: "pasarán / estos años -cuántos (o: ¡cuántos!)- de viento sucio / debajo del párpado -cuántos (o: ¡cuántos!)- del exilio") ${ }^{13}$. La puntuación sin marcas de esta parte del movimiento \#1 va acorde con un ritmo acelerado, urgente, sin pausas, indicando que no hay deseo de detenerse en estas líneas que hacen referencia al exilio, experiencia dolorosa. El ritmo se normaliza en los movimientos siguientes y llega a ser totalmente normal en cuanto a sentido y puntuación en las dos oraciones finales.

Se ha visto, entonces, que estos dos poemas entregan dos visiones y dos experiencias diferentes del exilio, lo cual no debe sorprender. Los estudiosos constatan la diversidad de experiencias entre quienes sufren el exilio: "cada exilio se origina de diferentes maneras, que se viven de modo particular e intransferible"; "las ramificaciones que derivan [del exilio] son tan heterogéneas como el número de personas que se ven obligadas a vivir fuera de sus naciones" (Gutiérrez 2006: 26). En el caso de Gonzalo Rojas, el diferente entorno en que se producen ambos poemas augura más disimilitudes que semejanzas en el tratamiento del tema, que es lo que sucede: las acciones transcurren en un país de cultura germánica en "Domicilio", mientras que, datos externos, como vimos, sitúan "Transtierro" en un país de cultura hispana. Aun así, hay unos pocos rasgos comunes en ambos poemas. Se puede anotar primeramente la comprensible angustia de una futura muerte fuera de la tierra natal. A las líneas de "Domicilio" que leen: "Envejecer así, pasar veinte años de cemento / previo al otro", les hace eco la oración de "Transtierro" que presiente: "comeré tierra / de la Tierra bajo las tablas / del cemento". De modo semejante el desconsuelo de estar en tierra extranjera se mienta explícitamente en "Domicilio" ("esta pena"), y se infiere por el contenido del primer movimiento de "Transtierro" con su "viento sucio" y con su exilio sin vista "debajo del párpado (...) del exilio".

Entre los dos poemas existen, sin embargo, diferencias notorias, la mayoría por rasgos que están presentes en un poema y ausentes en el otro. En "Domicilio" aparece un entorno geográfico y sociocultural preciso, mentado, entre otros datos, por la palabra Báltico del título, y la triple repetición del idioma, el alemán. "Transtierro"

Pellegrini se deja llevar por la puntuación anómala e indica que, excluyendo los últimos tres versos, el poema es "una sola frase que cae sinuosa por la página y no se interrumpe siquiera por las divisiones estróficas" (2013: 193).

13 Este adverbio 'cuántos' podría también tener valor interrogativo. En el citado "Sobre el poema 'Transtierro"” (1984: 92-94) hay más detalles acerca de este modificativo. 
no entrega clave alguna que permita asignar al poema un lugar específico, sólo datos externos, se ha dicho, sitúan el poema en Venezuela. "Domicilio" detalla los muchos aspectos del angustioso vivir inmerso en lengua y cultura extrañas: su tráfico ("entre / tranvía y tranvía"), su ruido sinestésico de "estridencia amarilla", su exactitud ("las 5.03"), los quehaceres repetitivos ("barrer (...) / la escalera cada semana"), la substitución del nombre por un número ("ser exacto y silencioso en mi número"); todo este modo de vida no tiene correlato en "Transtierro". En "Domicilio" se hace alusión explícita a la falta de libertad ("tirar la libertad / a la basura") en que vive el hablante, lo cual implica una crítica implícita al sistema político imperante. El campo político no aparece en "Transtierro", tal vez porque durante el período en que el poeta permaneció en ese país el régimen vigente era distinto al de la República Democrática Alemana: entre 1974 y 1979 Venezuela tenía un gobernante del partido de Acción Democrática.

La parte final de ambos poemas exhibe también diferencias. En "Domicilio" asistimos al torpe e irónico agradecimiento del hablante por la acogida que se le ha brindado. Sabe que debe agradecer, piensa que debe agradecer en alemán y supone que el agradecimiento debe ir dirigido a Alguien, quienquiera sea ese alguien: "agradecer, / sobre todo en alemán agradecer, / supongo, a Alguien". El final de "Transtierro", especialmente la última línea con el triple vocablo "parto", contiene ideas de despedida, que puede indicar término de vida, pero también de nacimiento, lenguaje más consolador.

En un campo lingüístico formal, la parquedad en la morfología de formas verbales finitas en "Domicilio", un único "Tendré que" inicial que marca la obligación, contrasta con la mayor variedad de formas finitas en "Transtierro": "miro", "soy" y tal vez "parto" en presente; "pasarán", "comeré", el cuádruple "me haré" y "seré" en futuro. Este contraste es marca formal de la relativa simplicidad semántica de "Domicilio" que ya hemos anotado, frente a la densidad semántica de "Transtierro". En "Transtierro" el futuro alude primeramente a la extensión temporal del exilio: "pasarán / estos años (...) del exilio", generalmente entendida como extensión sin término. El segundo tiempo futuro anticipa la muerte en un momento posterior: "comeré tierra / de la Tierra". El tercer tiempo futuro, "me haré", repetido, registra el importante inventario de los avatares del hablante, quien pasará por estados materiales y concretos (ojo, mar con su oleaje y su roca, hueso) hasta llegar al estado final inmaterial y atemporal de la música, de la poesía. En cuanto al tiempo presente, la primera ocurrencia -"Miro el aire en el aire"- indica simplemente el instante de la enunciación por parte del hablante, la penosa constatación de un estado de vacuidad. La segunda instancia -"Parto / soy"- es la negación de la muerte mencionada antes. La última línea, el triple y ambiguo "parto" del verso final, une, como vimos, el sentido del sustantivo y el de la forma verbal: es así tanto el momento de la despedida final como el del parto perpetuo.

El hablante de "Domicilio" es prisionero de un entorno odioso y degradante que seguirá repitiéndose; no puede superar la pesadumbre, la "esencial tristeza" del exilio que menciona Said (2005: 179). El hablante de "Transtierro", aunque alude a la vacuidad de su existencia e, indirectamente, al dolor que el exilio causa, es capaz de ir más allá de ese estadio opresor y de proyectarse hacia un futuro liberador en el cual, en último término, llegará a ser su poesía. El arte le ha permitido exorcizar y transcender el aquí y el ahora. 


\section{OBRAS CITADAS}

Apollinaire, Guillaume. 1987. Caligramas. Madrid: Cátedra.

Ascunce, José Ángel. 2002. "El exilio como realidad plural. Emigración, transtierro y exilio. Francia y América como ejemplos". En Alted Vigil, Alicia y Manuel Aznar Soler (Eds.), Literatura y cultura del exilio español de 1939 en Francia. Alicante: Biblioteca Virtual Miguel de Cervantes. 262-275.

Bada, Ricardo. 2011. "Primer 20.12 sin Gonzalo Rojas: Homenaje al poeta". El Espectador (Bogotá, Colombia). Recuperado el 18 de junio de 2015, de http://www.elespectador. com/noticias/cultura/primer-2012-sin-gonzalo-rojas-articulo-317597

Cymerman, Claude. 1993. "La literatura hispanoamericana y el exilio". Revista Iberoamericana LIX.164/165: 523-550.

Foffani, Enrique. 2002. "Veinte botellas de pisco: Entrevista con Gonzalo Rojas". Clarín (Buenos Aires, Argentina). Recuperado el 21 de junio de 2015, de http://edant.clarin.com/ suplementos/cultura/2002/08/17/u-00211.htm

Giordano, Enrique. 1987. "Gonzalo Rojas: Variaciones del exilio". En Giordano, Enrique (Ed.), Poesía y poética de Gonzalo Rojas. Santiago: Monografías del Maitén. 207-215.

Gutiérrez, José Ismael. 2006. "Del exilio y otros demonios: La literatura hispanoamericana en fuga”. Revista de Estudios Hispánicos 33.2: 17-33.

Huidobro, Vicente. 1941. Ver y palpar. Santiago: Ercilla.

May, Hilda R. 1991. La poesía de Gonzalo Rojas. Madrid: Hiperión.

Pellegrini, Marcelo. 2013. La ficción suprema: Gonzalo Rojas y el viaje a los comienzos. Santiago: Editorial Cuarto Propio.

Rojas, Gonzalo. 1977. Oscuro. Caracas: Monte Ávila. 1979. Transtierro. Madrid: Ediciones Taranto. 1988. Materia de testamento. Madrid: Hiperión. 1999. Obra selecta. Caracas: Biblioteca Ayacucho. 2010. Con arrimo y sin arrimo. Santiago: Editorial Pfeiffer. 2010. El sol es la única semilla. Bogotá: Universidad Externado de Colombia. 2013. Íntegra. Obra poética completa. México D.F.: Fondo de Cultura Económica.

Rojas, Nelson. 1984. "Sobre el poema 'Transtierro"'. En Rojas, Nelson, Estudios sobre la poesía de Gonzalo Rojas. Madrid: Playor. 89-106.

Rojas-Mackenzie, Rodrigo. s/f. "Breve cronología de Gonzalo Rojas". Recuperado el 21 de junio de 2015, de http://www.memoriachilena.cl/archivos2/pdfs/MC0067494.pdf

Said, Edward. 2005. Reflexiones sobre el exilio y otros ensayos literarios y culturales. Barcelona: Random House Mondadori. 
